\title{
Fabrication by Inclined-Substrate Deposition of Biaxially Textured Buffer Layer for Coated Conductors*
}

U. Balachandran, B. Ma, M. Li, R. E. Koritala, B. L. Fisher, R. Erck, and S. E. Dorris

Energy Technology Division, Argonne National Laboratory

Argonne, Illinois 60439

November 2001

The submitted manuscript has been created by the
University of Chicago as Operator of Argonne
National Laboratory ("Argonne") under Contract No.
W-31-109-ENG-38 with the U.S. Department of
Energy. The U.S. Government retains for itself, and
others acting on its behalf, a paid-up, nonexclusive,
irrevocable worldwide license in said article to
reproduce, prepare derivative works, distribute
copies to the public, and perform publicly and
display publicly, by or on behalf of the Government.

Keywords: YBCO thin film, Coated conductor, Inclined substrate deposition, Biaxial texture

Invited paper to be submitted for publication in the Proceedings of the Materials Research Society Fall 2001 Meeting, Boston, MA, Nov. 25-29, 2001.

*Work supported by the U.S. Department of Energy (DOE), Energy Efficiency and Renewable Energy, as part of a DOE program to develop electric power technology, under Contract W-31-109-Eng-38. 


\title{
Fabrication by Inclined-Substrate Deposition of Biaxially Textured Buffer Layer for Coated Conductors
}

\author{
U. Balachandran, B. Ma, M. Li, R. E. Koritala, B. L. Fisher, R. A. Erck, and S. E. Dorris \\ Energy Technology Division, Argonne National Laboratory, Argonne, IL 60439
}

\begin{abstract}
Inclined substrate deposition (ISD) offers the potential for rapid production of high-quality biaxially textured buffer layers suitable for YBCO-coated conductors. We have grown biaxially textured $\mathrm{MgO}$ films by ISD at deposition rates of 20-100 $\AA / \mathrm{sec}$. Columnar grain structures with a roof-tile-shaped surface were observed in the ISD-MgO films. X-ray pole figure analysis revealed that the (002) planes of the ISD-MgO films are titled at an angle from the substrate normal. A small phi-scan full-width at half maximum (FWHM) of $\approx 9^{\circ}$ was observed on $\mathrm{MgO}$ films deposited at an inclination angle of $55^{\circ}$. YBCO films were also grown on ISD-MgObuffered Hastelloy substrates by pulsed laser deposition. We obtained a critical current density of $\approx 2 \times 10^{5} \mathrm{~A} / \mathrm{cm}^{2}$ at $77 \mathrm{~K}$ in self-field on 0.5 - $\mu \mathrm{m}$-thick, 0.5 -cm-wide, 1 -cm-long samples. This work has demonstrated that biaxially textured ISD MgO buffer layers deposited on metal substrates are promising candidates for fabrication of high-quality YBCO-coated conductors.
\end{abstract}

\section{INTRODUCTION}

The development of $\mathrm{YBa}_{2} \mathrm{Cu}_{3} \mathrm{O}_{7-\delta}(\mathrm{YBCO})$ coated conductor technology will make possible the design and fabrication of smaller, lighter, and more efficient power devices, such as motors, generators, transformers, transmission cables, and fault-current limiters, that can be operated at temperatures that approach the temperature of liquid nitrogen [1-3]. To meet the needs of the U.S. electric power industry, enormous effort has been expanded in the past few years to accelerate the processing, fabrication, and manufacturing of high-temperature superconductors and coated conducting wires [4]. Highly textured template films or buffer layers are necessary to successfully deposit biaxially aligned YBCO films on flexible metal substrates and thereby achieve high critical current density $\left(\mathrm{J}_{\mathrm{c}}\right)$. Several techniques including ion-beam-assisted deposition (IBAD), rolling-assisted biaxially textured substrates (RABiTS), and inclinedsubstrate deposition (ISD), have been developed [5-7]. YBCO films have been deposited on the buffered substrates by pulsed laser deposition (PLD), chemical vapor deposition, or electronbeam (e-beam) coevaporation methods [8-10]. When compared with IBAD and RaBiTS, the ISD process produces textured films at high deposition rates (20-100 $\mathrm{A} / \mathrm{sec})$ and is independent of recrystallization properties of the metallic substrates. It is also simpler (without the need of an assisting ion source) and easier to accomplish.

Magnesium oxide $(\mathrm{MgO})$ thin films deposited on inclined substrates were first observed to exhibit preferred orientation by Aboelfotoh in 1973 [11]. Recently, Bauer et al. reported the use of the ISD to fabricate $\mathrm{MgO}$ buffer layers for coated-conductor applications [12]. We grew biaxially textured $\mathrm{MgO}$ thin films on mechanically polished Hastelloy C276 (HC) substrates by ISD with an e-beam evaporation system. To decrease the surface roughness of the as-deposited ISD $\mathrm{MgO}$ films, an additional thin layer of $\mathrm{MgO}$ was deposited at an elevated temperature and a zero inclination angle. YBCO films were subsequently deposited on these ISD-MgO-buffered substrates with an excimer laser system. The surface morphology of the films was investigated 
by scanning electron microscopy (SEM) and atomic force microscopy (AFM). The crystalline orientation of the film was studied by transmission electron microscopy (TEM). X-ray pole figures, $\phi$-scan and $\omega$-scan were used to analyze texture. In this paper, we discuss the growth mechanism, microstructure, and dependence of the biaxial alignment of ISD MgO thin films on the substrate inclination angle, and report the superconducting properties of YBCO deposited on biaxially textured ISD MgO buffer layers fabricated on polished $\mathrm{HC}$ substrates.

\section{EXPERIMENTAL PROCEDURES}

Mechanically polished $\mathrm{HC}$ pieces $\approx 0.1 \mathrm{~mm}$ thick, $\approx 5 \mathrm{~mm}$ wide, and $1 \mathrm{~cm}$ long were used as substrates for ISD of $\mathrm{MgO}$ and subsequent YBCO deposition. A schematic illustration of the experimental setup is in Fig. 1. $\mathrm{MgO}$ thin films were grown from an $\mathrm{MgO}$ source by e-beam evaporation. Fused lumps of $\mathrm{MgO}$ (Alfa Aesar, 99.95\% metals basis, 3-12 mm pieces) were used as the target material. The substrates were mounted on a tiltable sample stage above the e-beam evaporator. The substrate inclination angle $\alpha$, substrate normal with respect to the evaporation direction, was varied between 10 and $70^{\circ}$ (see Fig. 1). Oxygen flow was introduced into the system during film deposition. The base pressure of the vacuum system was $1 \times 10^{-7}$ torr, which

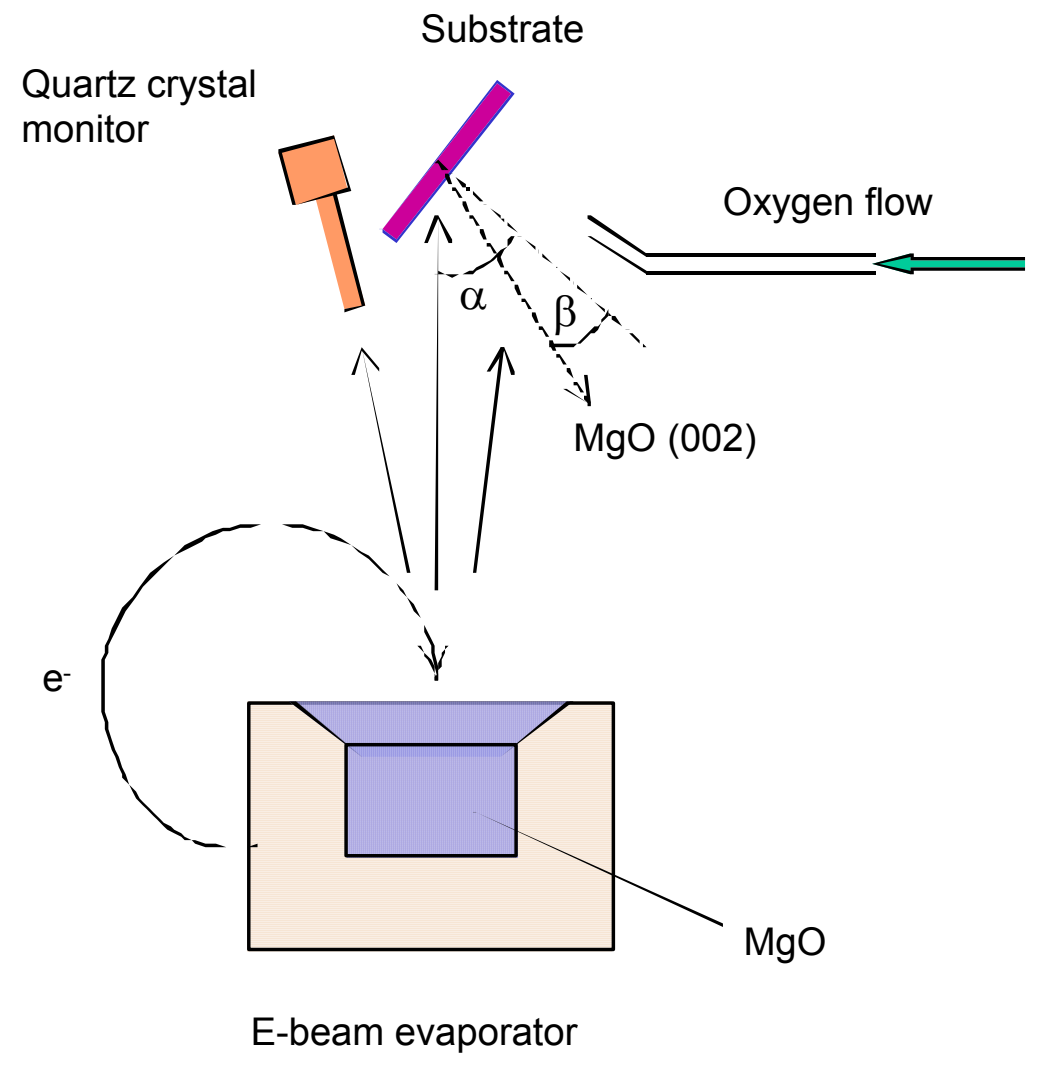

Figure 1. Schematic illustration of experimental setup for inclined-substrate deposition. 
rose to $\approx 2 \times 10^{-5}$ torr during deposition. A quartz crystal monitor was mounted beside the sample stage to monitor and control the deposition rate. High deposition rates of $20-100 \AA / \mathrm{sec}$ were used, and the substrate temperature was maintained between room temperature and $50^{\circ} \mathrm{C}$ during deposition. After the deposition of ISD films, a thin layer of $\mathrm{MgO}$ was deposited at a zero-degree inclination angle at elevated temperatures to reduce the surface roughness of the buffer layer with respect to epitaxial YBCO growth.

YBCO films were deposited by the PLD method with a Lambda Physik LPX 210i excimer laser, with a $\mathrm{Kr}-\mathrm{F}_{2}$ gas premixture as the lasing medium. Commercial YBCO targets (Superconductive Components, 99.999\% pure), $22 \mathrm{~mm}$ in diameter and $6 \mathrm{~mm}$ thick, were used. Substrates were attached to a heatable sample stage with silver paste and heated to a high temperature $\left(700-800^{\circ} \mathrm{C}\right)$ during deposition. The size of laser spot focused at the rotating target was $\approx 8 \mathrm{~mm}^{2}$, which produced an energy density of $\approx 2.5 \mathrm{~J} / \mathrm{cm}^{2}$. The distance between the target and the substrates was $7.5 \mathrm{~cm}$. The desired oxygen partial pressure (in the range of 100-300 mtorr) was obtained by flowing ultra-high-purity oxygen through the chamber.

The superconducting critical transition temperature $\left(\mathrm{T}_{\mathrm{c}}\right)$ and $\mathrm{J}_{\mathrm{c}}$ were determined by the inductive method and confirmed by the transport method at $77 \mathrm{~K}$ in liquid nitrogen. The inductive test is used as a standard characterization tool to measure the superconducting properties of YBCO films. Thin-film superconductor samples were placed between a primary and secondary coil pair with an inner diameter of $1 \mathrm{~mm}$ and an outer diameter of $5 \mathrm{~mm} .1 \mathrm{kHz}$ alternating current was introduced to the primary coil and detected from the secondary coil by a lock-in amplifier (Stanford Research Systems SR830 DSP). Samples used for transport measurements were first coated with $2-\mu \mathrm{m}$-thick silver by e-beam evaporation and then annealed in flowing high-purity oxygen at $400^{\circ} \mathrm{C}$ for $2 \mathrm{~h}$. Typical samples used for four-probe transport measurement were $3-5 \mathrm{~mm}$ wide and $1 \mathrm{~cm}$ long.

The film texture was characterized by $\mathrm{X}$-ray diffraction pole figure analysis using $\mathrm{Cu}-\mathrm{K}_{\alpha}$ radiation. In-plane texture was characterized by the FWHM of $\phi$ scans for the $\mathrm{MgO}(002)$ reflection $\left(2 \theta=42.9^{\circ}\right)$, and out-of-plane texture was characterized by the FWHM of $\omega$ scans at the $\mathrm{MgO}$ [001] pole for the same reflection. Surface morphology and crystalline orientation of $\mathrm{MgO}$ films were investigated by SEM and TEM.

\section{RESULTS AND DISCUSSION}

Plan-view SEM revealed (Fig. 2a) a roof-tile structure for an ISD MgO film deposited at room temperature with $\alpha=55^{\circ}$. Columnar grains nearly perpendicular to the substrate surface were observed on the cross-sectional fracture surface (Fig. 2b). The MgO grain size increased when the film grew for the first 0.25 - $\mu \mathrm{m}$ thickness of film; it then became stabilized at $\approx 0.1 \mu \mathrm{m}$, without noticeable change in size when the film grew further in thickness.

The biaxial texture of the ISD MgO films was characterized by X-ray diffraction pole figure analysis. Typical pole figures of a $1.5-\mu \mathrm{m}$-thick ISD $\mathrm{MgO}$ film deposited at $\alpha=55^{\circ}$ are shown in Fig. 3. Unlike YSZ films prepared by inclined-substrate PLD [8], where the (001) planes are nearly parallel to the substrate surface, the [001] axis of the ISD MgO buffer layer is tilted 


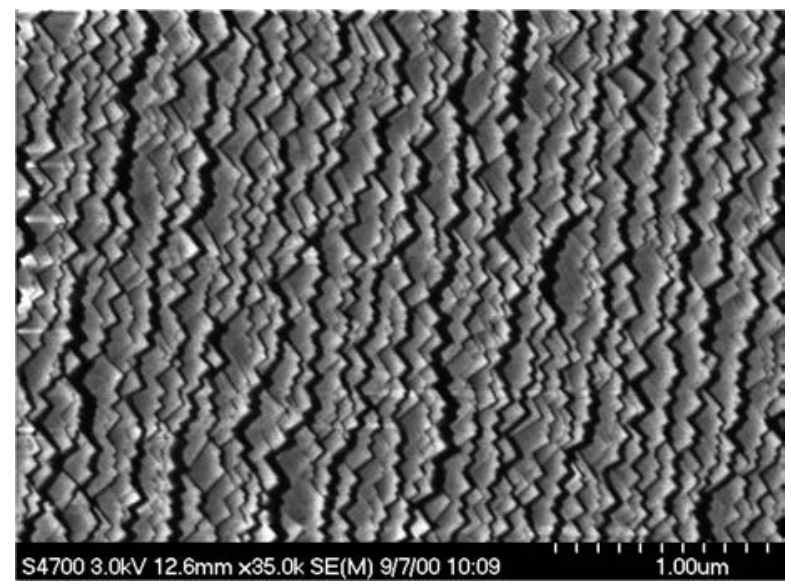

(a)

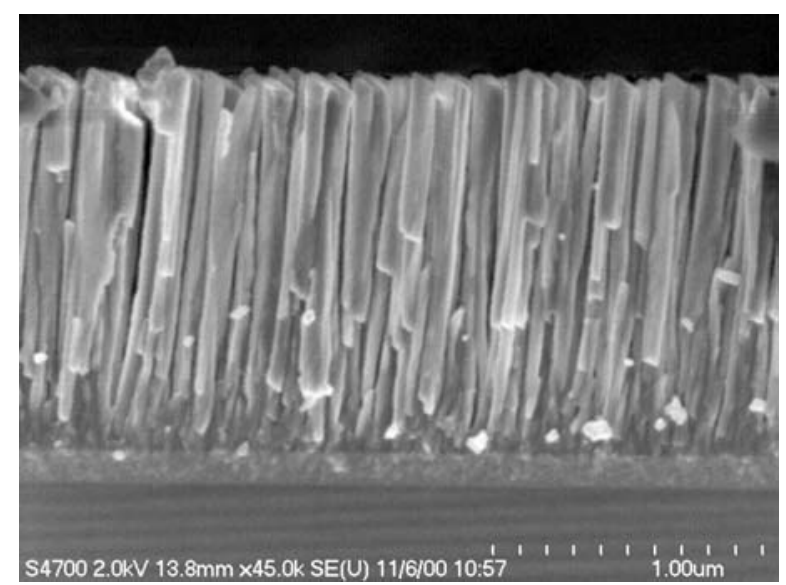

(b)

Figure 2. (a) Plan view and (b) cross-sectional SEM images of ISD MgO film deposited at $\alpha=55^{\circ}$.

away from the substrate normal. The asymmetric distribution of the pole peaks reveals that the $\mathrm{MgO}$ (001) planes have a tilt angle $\beta$ toward the deposition direction. These ISD MgO films exhibit good texture; distinct in-plane alignment can be seen by the well-defined poles for not only the [001] axis but also the [010] and [100] axes in Fig. 3. The tilt angle for the (001) plane was determined from the chi angle value of the [001] reflection in the $\mathrm{MgO}(002)$ pole figure. Out-of-plane alignment was characterized by an $\omega$ scan; data were taken at the [001] pole.
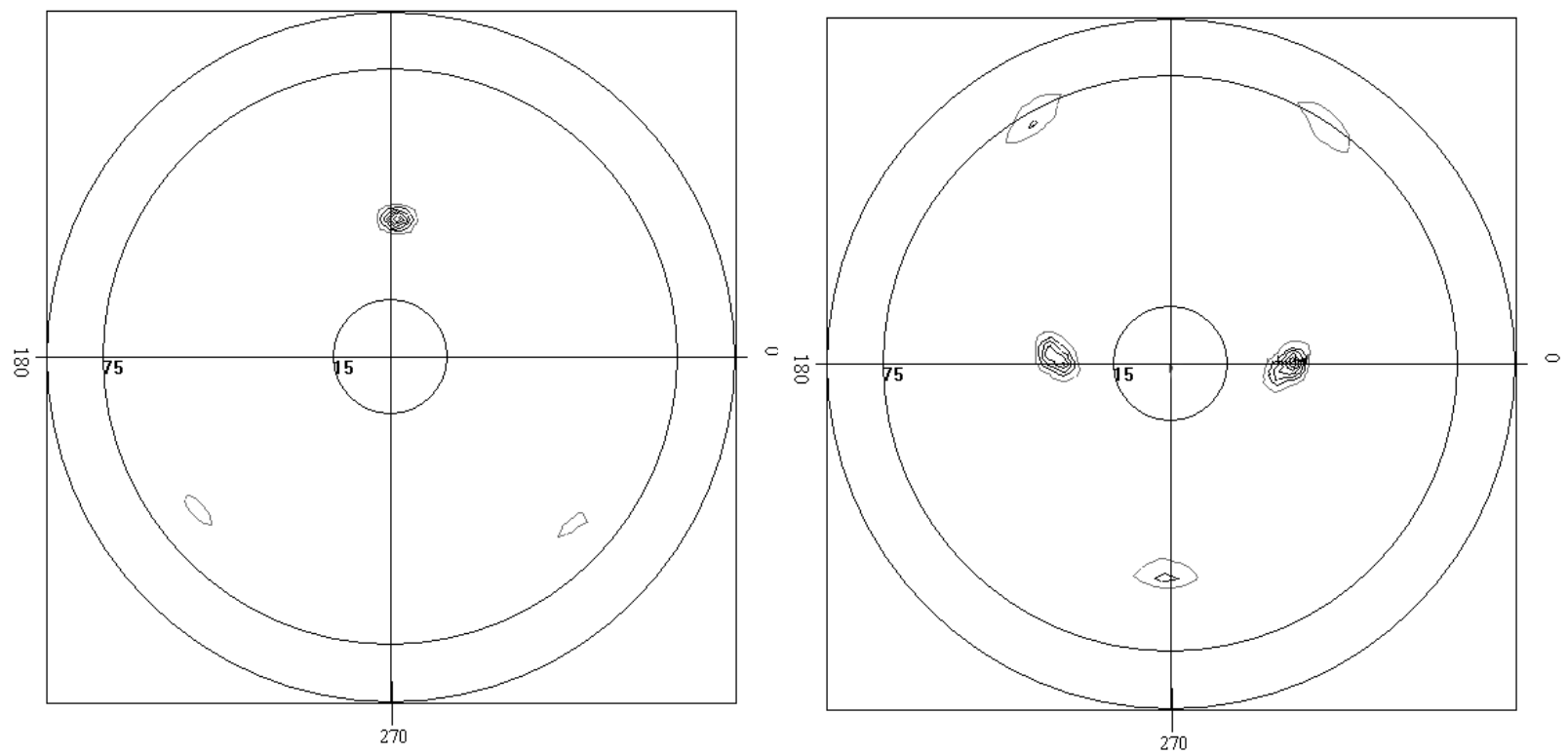

Figure 3. (a) $\mathrm{MgO}(002)$ and (b) $\mathrm{MgO}$ (220) pole figures for $\approx 1.5-\mu \mathrm{m}$-thick ISD $\mathrm{MgO}$ film deposited at room temperature with $\alpha=55^{\circ}$. 


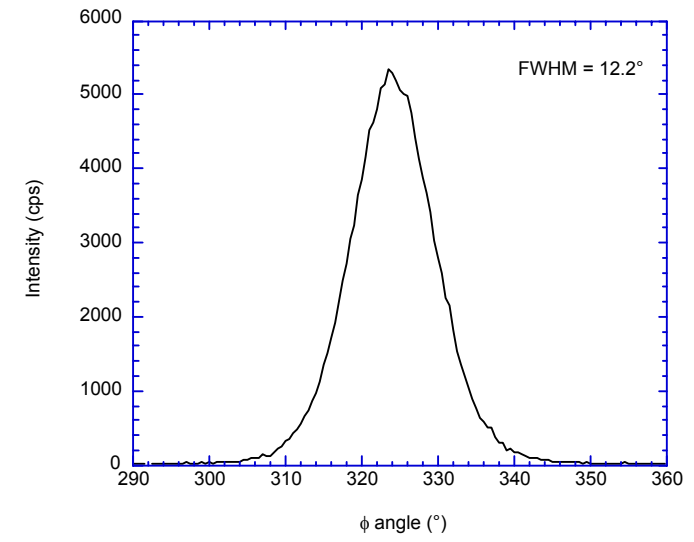

(a)

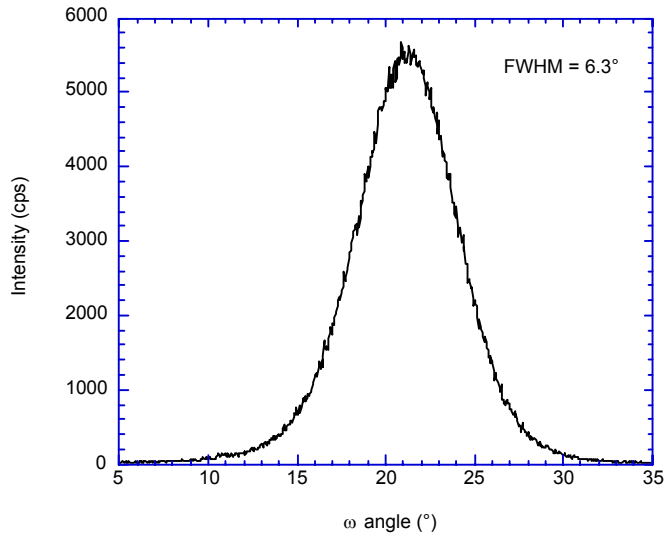

(b)

Figure 4. $\mathrm{MgO}(002)$ (a) $\phi$ - and (b) $\omega$-scan patterns for a 1.5- $\mu$ m-thick ISD $\mathrm{MgO}$ film deposited at $\alpha$ $=55^{\circ}$.

Figure 4 shows typical $\phi$ - and $\omega$-scan patterns for the ISD MgO film deposited at $\alpha=55^{\circ}$. The FWHMs for the $\phi$ - and $\omega$-scans and the tilt angles for the ISD MgO films made at various inclination angles are listed in Table 1. The smallest MgO (002) $\phi$-scan FWHM $\left(12.2^{\circ}\right)$ occurred for samples deposited when $\alpha=55^{\circ}$, and the smallest MgO (002) $\omega$-scan FWHM $\left(5.6^{\circ}\right)$ occurred for samples deposited when $\alpha=30^{\circ}$, with slightly larger FWHM values at higher or lower $\alpha$ angles. The tilt angles $\beta$ for these films are 22 and $32^{\circ}$, respectively.

Table. 1. Tilt angle and FWHMs ${ }^{\mathrm{a}}$ of $\phi$ - and $\omega$-scans for ISD MgO films deposited at various inclination angles.

\begin{tabular}{cccc}
\hline Incline Angle $\alpha\left(^{\circ}\right)$ & Tilt Angle $\beta\left(^{\circ}\right)$ & $\phi$-FWHM $\left(^{\circ}\right)$ & $\omega$-FWHM $\left(^{\circ}\right)$ \\
\hline 10 & 16 & 37.8 & 9.5 \\
15 & 16 & 47.2 & 11.3 \\
20 & 17 & 20.2 & 5.9 \\
25 & 17 & 23.4 & 6.8 \\
30 & 22 & 14.4 & 5.6 \\
35 & 18 & 19.4 & 6.4 \\
40 & 16 & 35.5 & 10.5 \\
45 & 20 & 39.3 & 12.5 \\
50 & 24 & 27.4 & 11.3 \\
55 & 32 & 12.2 & 6.3 \\
60 & 28 & 14.1 & 6.6 \\
65 & 32 & 12.8 & 6.9 \\
70 & 37 & 13.8 & 7.8 \\
\hline
\end{tabular}

${ }^{\mathrm{a}}$ As determined for $\mathrm{MgO}(002)$. 


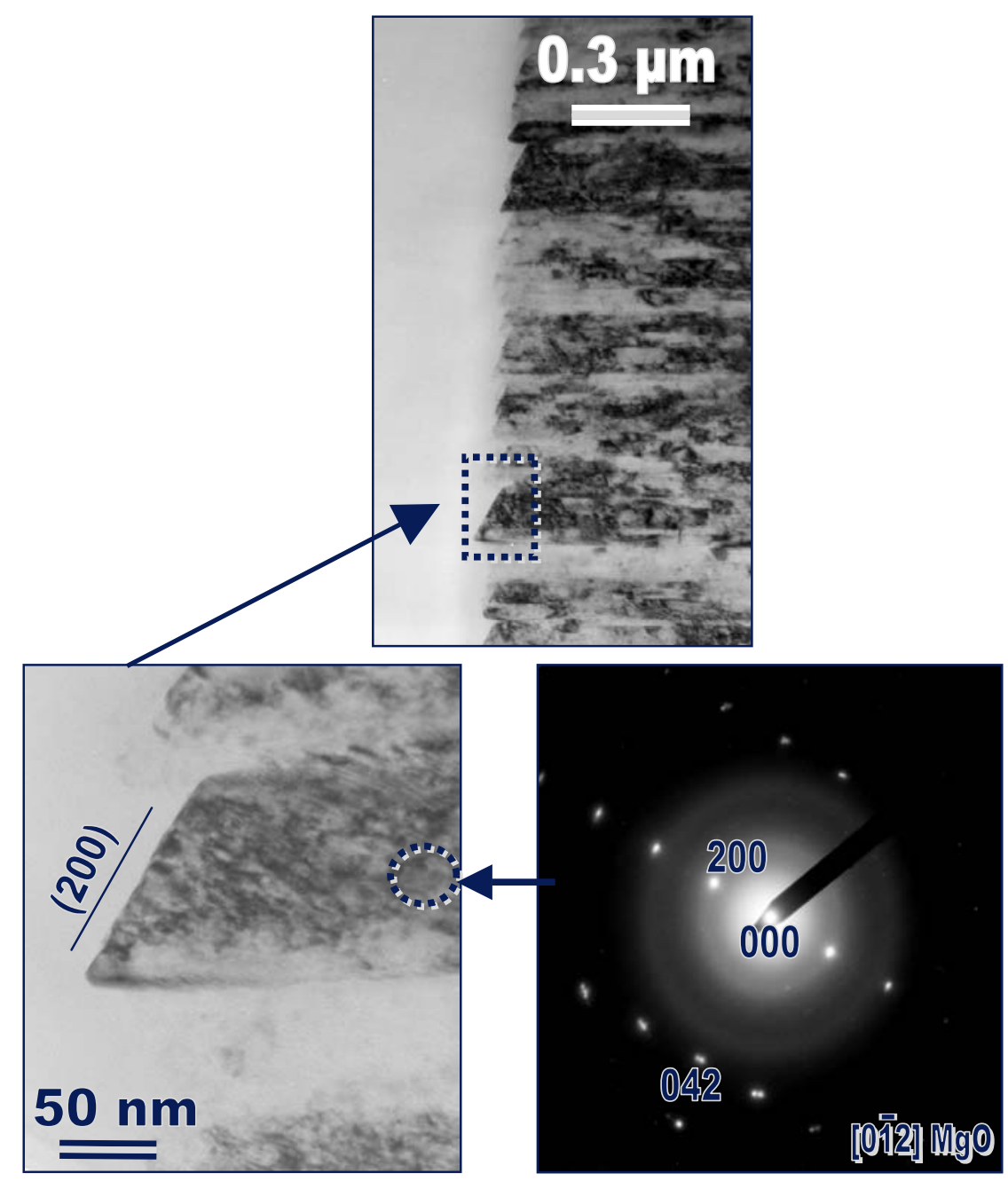

Figure 5. Facet of (200) plane on top of $\mathrm{MgO}$ columnar grain and corresponding SAD pattern in film deposited with $\alpha=55^{\circ}$.

The film tilt angle increases with increasing substrate inclination angle, as shown in Table 1. This finding implies that $\beta$ cannot be independently adjusted without affecting the texture of the films. Because the best in-plane texture was obtained with $\alpha=55^{\circ}, \mathrm{MgO}$ films deposited with $\alpha=55^{\circ}$ were used for buffer layers and for the subsequent deposition of YBCO films by PLD. An interesting observation is that we obtained the smallest $\phi$-FWHM and $\omega$-FWHM at fairly large $\beta$ when compared with the adjacent values listed in the table.

Figure 5 shows a TEM image and selected area diffraction (SAD) pattern of MgO columnar grains in a film deposited with $\alpha=55^{\circ}$. The top facet of $\mathrm{MgO}$ grains is a (002) plane. Film morphology and texture evolution in the ISD MgO films can be understood from the selfshadowing effect. It has been demonstrated [13] that in-plane texture during polycrystalline film growth develops through a combination of fast growth along a certain crystallographic direction 


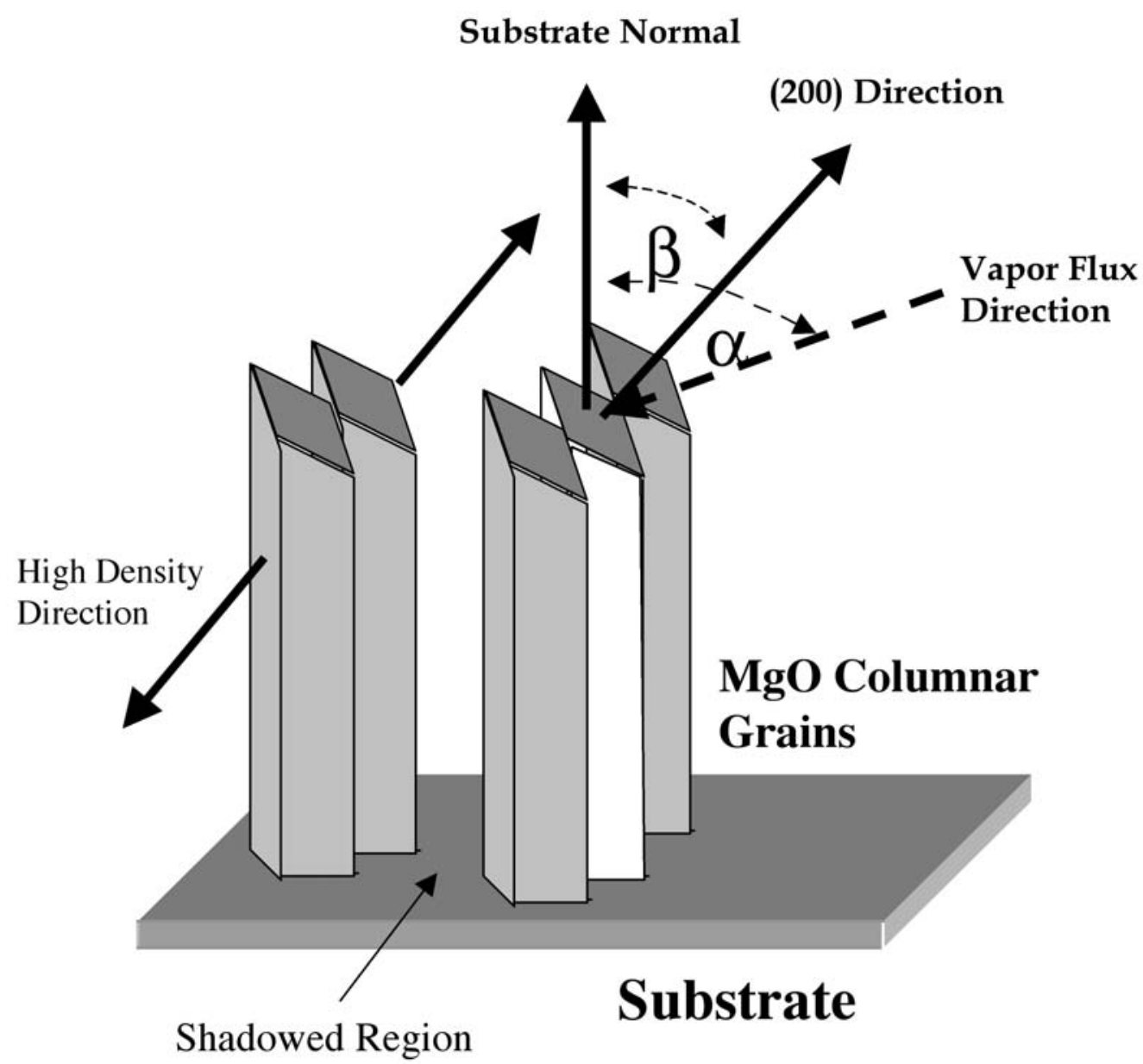

Figure 6. Schematic representation of ISD MgO growth mechanism due to shadowing effect.

and self-shadowing that occurs when deposition is at an inclined angle. In the case of $\mathrm{MgO}$, the fast growth plane is $\{200\}$ [14]. Because maximizing the (002) faces can decrease the surface free energy, the $\{200\}$ plane is also the equilibrium crystal habit, as confirmed by the cubic morphology exhibited in the $\mathrm{MgO}$ film [15]. With deposition at an inclined angle, the $\{200\}$ plane rotates toward the vapor source, so the (002) surface grows faster than other crystalline faces. A schematic representation of this grain growth mechanism is illustrated in Fig. 6.

To improve the surface roughness, an additional thin layer of $\mathrm{MgO}$ was deposited on the ISD $\mathrm{MgO}$ films at elevated temperatures $\left(600-800^{\circ} \mathrm{C}\right)$ by e-beam evaporation at zero-inclination angle $(\alpha=0)$. Figure 7 shows SEM images of the top plan-view and fracture cross-sectional view of a 1.5- $\mu \mathrm{m}$-thick ISD MgO layer deposited at room temperature with $\alpha=55^{\circ}$, followed by deposition of an additional $0.5-\mu \mathrm{m}$-thick $\mathrm{MgO}$ layer at $700^{\circ} \mathrm{C}$ with $\alpha=0^{\circ}$. 


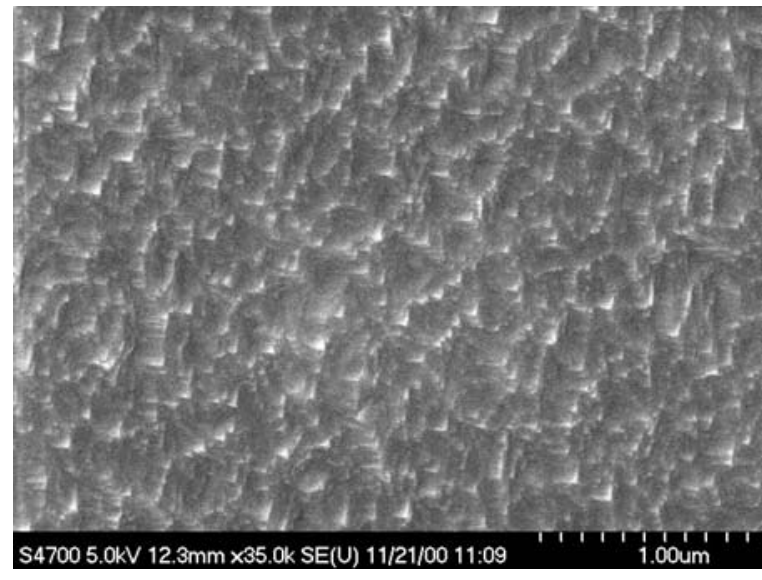

(a)

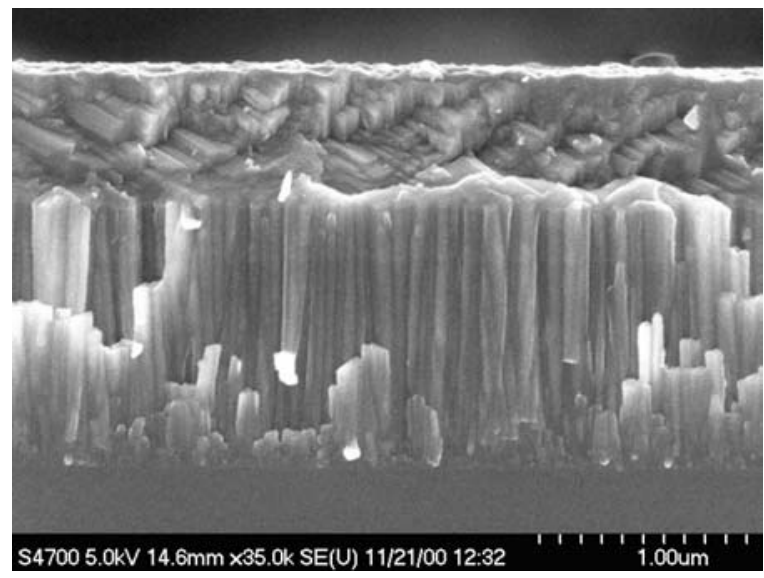

(b)

Figure 7. (a) Plan view and (b) cross-sectional SEM images of $\mathrm{MgO}$ film made of a layer of ISD MgO deposited at room temperature with $\alpha=55^{\circ}$, followed by an additional layer of $\mathrm{MgO}$ e-beam evaporated at $700^{\circ} \mathrm{C}$ with $\alpha=0^{\circ}$.

Table 2. FWHMs of $\phi$ and $\omega$ scans for ISD MgO films before and after deposition of homoepitaxial $\mathrm{MgO}$ layer at $700^{\circ} \mathrm{C}$.

\begin{tabular}{|c|c|c|c|c|c|c|}
\hline \multirow{2}{*}{ Sample } & \multicolumn{2}{|c|}{$\phi$-scan $\mathrm{MgO}(002){\mathrm{FWHM}\left({ }^{\circ}\right)}^{2}$} & \multicolumn{3}{c|}{$\omega$-scan MgO (002) FWHM $\left(^{\circ}\right)$} \\
\cline { 2 - 7 } & Before & After & $\begin{array}{c}\text { Differ- } \\
\text { ence }\end{array}$ & Before & After & $\begin{array}{c}\text { Differ- } \\
\text { ence }\end{array}$ \\
\hline 1 & 11.8 & 9.7 & 2.1 & 6.6 & 5.6 & 1.0 \\
\hline 2 & 11.6 & 9.8 & 1.8 & 7.0 & 5.8 & 1.2 \\
\hline 3 & 12.7 & 10.9 & 1.8 & 6.5 & 5.6 & 0.9 \\
\hline 4 & 13.2 & 9.2 & 4.0 & 6.8 & 5.4 & 1.2 \\
\hline
\end{tabular}

Figure 8 shows the $\phi$ - and $\omega$-scan patterns for $\mathrm{MgO}(002)$ after homoepitaxially growing a 0.5 - $\mu \mathrm{m}$-thick $\mathrm{MgO}$ layer on ISD $\mathrm{MgO}$ film at elevated temperature. Biaxial texture of the film was improved; FWHMs of 9.2 and $5.4^{\circ}$ were observed for $\mathrm{MgO}(002) \phi$ and $\omega$ scans, respectively. Surface smoothness of the film was also significantly improved. Plate-shaped grains were formed during the flat-substrate deposition at $700^{\circ} \mathrm{C}$, in contrast to columnar grains during ISD at room temperature, as shown in Fig. $7 \mathrm{~b}$. 


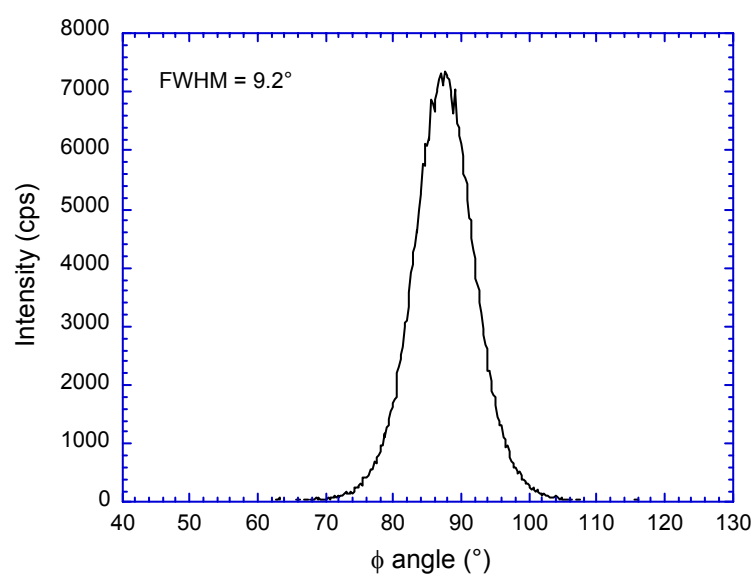

(a)

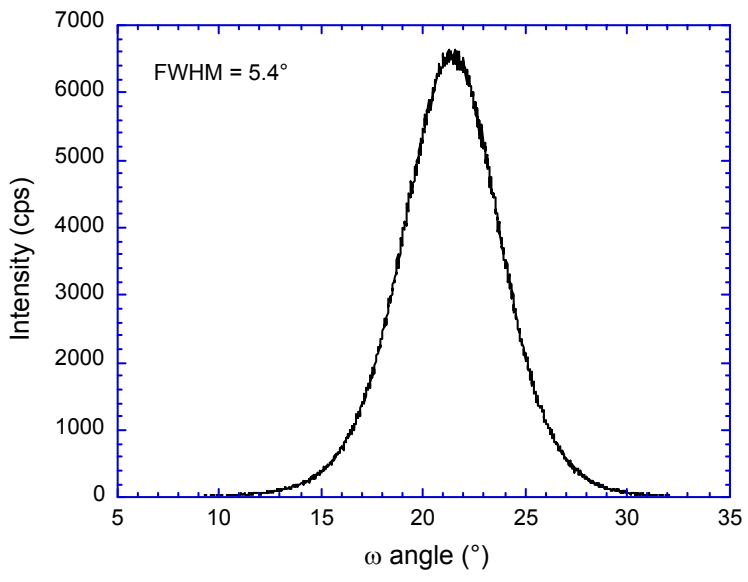

(b)

Figure 8. $\mathrm{MgO}(002)$ (a) $\phi$ - and (b) $\omega$-scan patterns after homoepitaxially growing 0.5 - $\mu \mathrm{m}$-thick $\mathrm{MgO}$ layer on ISD $\mathrm{MgO}$ film.

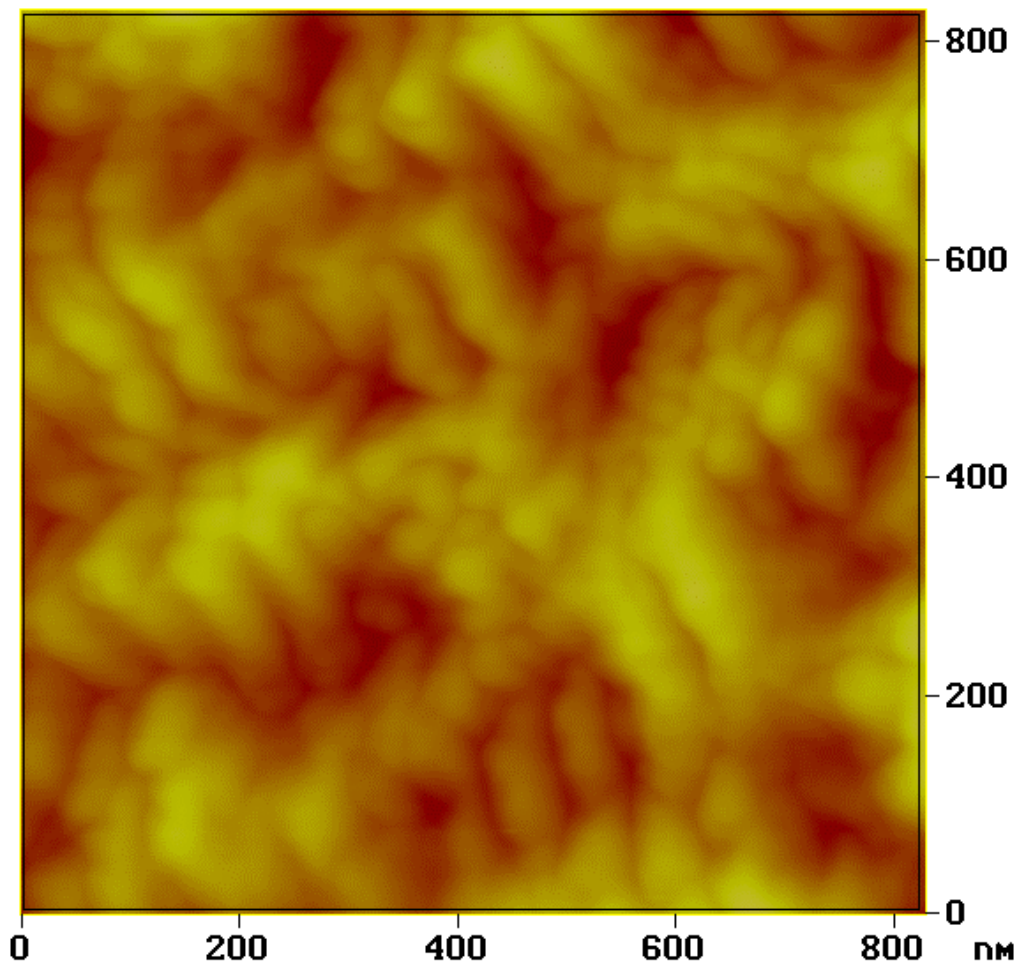

Figure 9. AFM image of a homo-epitaxial layer of $\mathrm{MgO}$ deposited at $700^{\circ} \mathrm{C}$ on $\mathrm{ISD} \mathrm{MgO}$ film. 
Table 2 lists the FWHMs for several ISD MgO films before and after flat substrate deposition of an additional $0.5 \mu \mathrm{m}$ layer of $\mathrm{MgO}$ at $700^{\circ} \mathrm{C}$. We observed $\approx 2$ and $\approx 1^{\circ}$ improvements in FWHMs from the MgO (002) $\phi$ and $\omega$ scans, respectively. An AFM image of the top homoepitaxial $\mathrm{MgO}$ layer is shown in Fig. 9. AFM analysis revealed that the root-meansquare (RMS) surface roughness of the $\mathrm{MgO}$ films improved from $\approx 28 \mathrm{~nm}$ to $\approx 10 \mathrm{~nm}$ after deposition of the homoepitaxial layer.

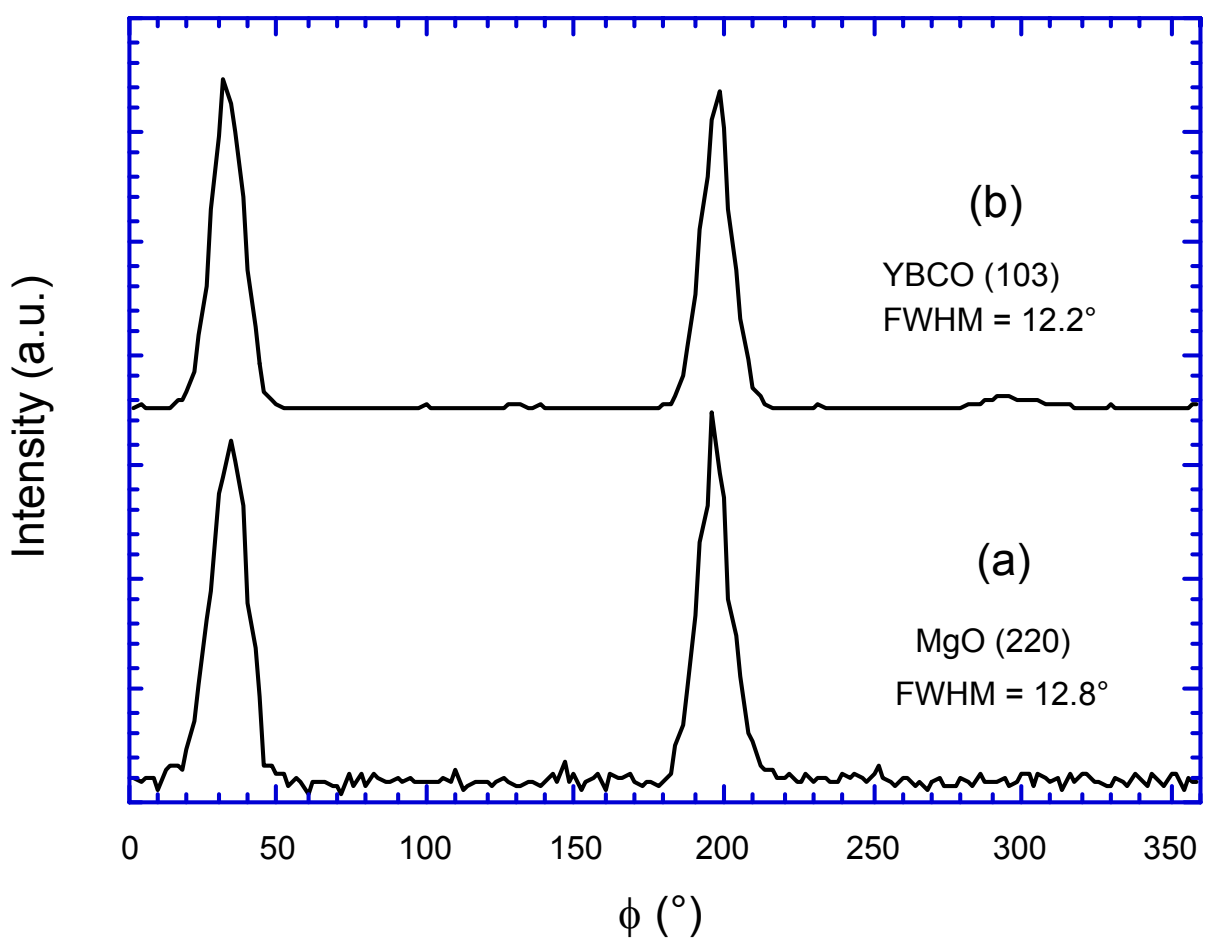

Figure 10. $\phi$-scan patterns of $\mathrm{MgO}(220)$ and $\mathrm{YBCO}$ (103), showing epitaxial growth.

Biaxially aligned YBCO films were successfully deposited on ISD-MgO-buffered HC substrates by PLD. Figure 10 shows $\phi$-scans for the MgO (220) and YBCO (103) films grown on the MgO-buffered HC substrate; it reveals epitaxial growth, with cubic-on-cubic biaxial alignment: YBCO [001] // MgO [001] and YBCO [100] // MgO [100] (or MgO [010]). The FWHMs of the YBCO films were generally $1-2^{\circ}$ smaller than those of the MgO films underneath; the FWHMs of MgO buffer layers on which YBCO films had been deposited were also slightly smaller. This finding may represent a bulk value due to larger penetration depth of the X-ray; a similar finding was reported by Bauer et al. [11]. 


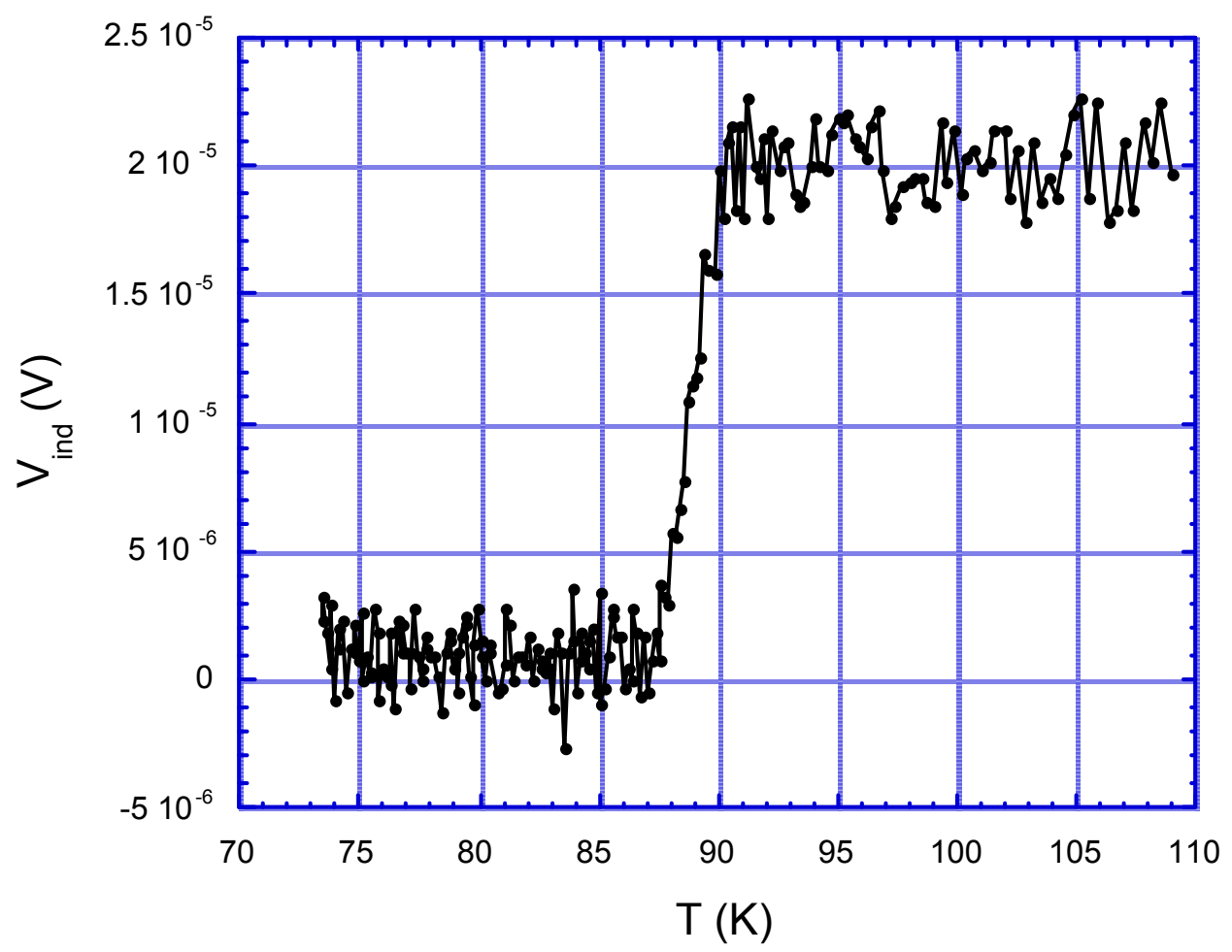

Figure 11. Critical-temperature transition curve for YBCO film deposited on ISD-MgO-buffered HC substrate.

To improve lattice mismatch, and therefore, enhance the superconducting properties of YBCO films, YSZ and $\mathrm{CeO}_{2}$ buffer layers were deposited by PLD on an MgO surface before the deposition of YBCO. Details of buffer layer architecture is reported elsewhere [16]. We obtained $\mathrm{T}_{\mathrm{c}}=90 \mathrm{~K}$ for a $0.5-\mu \mathrm{m}$-thick YBCO film deposited on an MgO-buffered HC substrate. From inductive measurements, Fig. 11 shows that the superconducting transition was complete at $88 \mathrm{~K}$. A transport $\mathrm{J}_{\mathrm{c}}$ of $\approx 2 \times 10^{5} \mathrm{~A} / \mathrm{cm}^{2}$ was measured at $77 \mathrm{~K}$ in self-field on a sample $0.5 \mu \mathrm{m}$ thick, $0.5 \mathrm{~cm}$ wide, and $1 \mathrm{~cm}$ long.

\section{CONCLUSIONS}

Biaxially textured $\mathrm{MgO}$ films were successfully grown by the ISD method, which is much more time-efficient for fabrication of buffer layers when compared with the IBAD deposition of YSZ. MgO films grown by the ISD process contain columnar grains that terminate at the surface in (002) planes. Plan-view SEM revealed a roof-tile-shaped structure. An MgO (002) $\phi$ scan with FWHM $=12.2^{\circ}$ was observed for $2-\mu \mathrm{m}$-thick $\mathrm{MgO}$ thin films deposited with $\alpha$ $=55^{\circ}$, and an $\mathrm{MgO}(002) \omega$ scan with $\mathrm{FWHM}=5.6^{\circ}$ was observed for $\mathrm{MgO}$ thin films deposited with $\alpha=30^{\circ}$. Tilt angles $\beta=22$ and $32^{\circ}$ were observed for films deposited with $\quad \alpha=55^{\circ}$ and $30^{\circ}$, respectively. The surface roughness and biaxial texture of ISD MgO thin films were significantly improved by flat-substrate deposition of an additional thin layer of $\mathrm{MgO}$ at elevated temperatures. 
YBCO films grown on ISD-MgO-buffered $\mathrm{HC}$ substrates exhibited a sharp superconducting transition, with onset $\mathrm{T}_{\mathrm{c}}=90 \mathrm{~K}$ and $\mathrm{J}_{\mathrm{c}} \approx 2 \times 10^{5} \mathrm{~A} / \mathrm{cm}^{2}$ at $77 \mathrm{~K}$ in zero field. These results demonstrate that biaxially textured ISD $\mathrm{MgO}$ buffer layers deposited on metal substrates are excellent candidates for fabrication of high-quality YBCO-coated conductors.

\section{ACKNOWLEDGMENTS}

SEM/TEM analysis was performed in the Electron Microscopy Center for Materials

Research at Argonne National Laboratory. This work was supported by the U.S. Department of Energy (DOE), Energy Efficiency and Renewable Energy, as part of a DOE program to develop electric power technology, under Contract W-31-109-Eng-38.

\section{REFERENCES}

1. D. K. Finnemore, K. E. Gray, M. P. Maley, D. O. Welch, D. K. Christen, and D. M. Kroeger, Physica C, 320, 1-8 (1999).

2. Y. Iijima and K. Matsumoto, Supercond. Sci. Technol., 13, 68-81 (2000).

3. J. O. Willis, P. N. Arendt, S. R. Foltyn, Q. X. Jia, J. R. Groves, R. F. DePaula, P. C. Dowden, E. J. Peterson, T. G. Holesinger, J. Y. Coulter, M. Ma, M. P. Maley, and D. E. Peterson, Physica C, 335, 73 (2000).

4. "Coated Conductor Technology Development Roadmap," U.S. Department of Energy report, Superconductivity for Electric System Program, August, 2001.

5. Y. Iijima, N. Tanabe, O. Kohno, and Y. Okeno, Appl. Phys. Lett., 60, 769-771 (1992).

6. C. P. Wang, K. B. Do, M. R. Beasley, T. H. Geballe, and R. H. Hammond, Appl. Phys. Lett., 71, 2955 (1997).

7. X. D. Wu, R. E. Muenchausen, S. Foltyn, R. C. Estler, R. C. Dye, C. Flamme, N. S. Nogar, A. R. Garcia, J. Martin, and J. Tesmer, Appl. Phys. Lett., 56, 1481, 1990.

8. K. Hasegawa, K. Fujino, H. Mukai, M. Konishi, K. Hayashi, K. Sato, S. Honjo, Y. Sato, H. Ishii, and Y. Iwata, Appl. Supercond., 4, 487-493 (1996).

9. D. Dimos, P. Chaudhari, J. Mannhart, and F. K. Legouges, Phys. Rev. Lett., 61, 219-222 (1988).

10. D. Dimos, P. Chaudhari, and J. Mannhart, Phys. Rev. B, 41, 4038-4049 (1990).

11. M. O. Aboelfotoh, J. Vac. Sci. Technol., 10, 621 (1973).

12. M. Bauer, R. Semerad, and H. Kinder, IEEE Trans. Appl. Supercond., 9, 1502 (1999).

13. O. P. Karpenko, J. C. Bilello, and S. M. Yalisove, J. Appl. Phys., 82, 1397-1403 (1997).

14. A. F. Moodie and C. E. Warble, J. Crystal Growth, 10, 26-38 (1971).

15. R. E. Koritala, M. P. Chudzik, Z. Luo, D. J. Miller, C. R. Kannewurf, and U. Balachandran, IEEE Trans. Appl. Supercond., 11, 3473-3476 (2001).

16. B. Ma, M. Li, Y. A. Jee, B. L. Fisher, and U. Balachandran, Physica C, 2001 (in press). 